\title{
Study on M\&As performance of iron and steel enterprises based on SEM
}

\author{
Yin Aiwei ${ }^{1, a}$, Xu Congwei ${ }^{1}, \mathrm{Xu}$ Yujie $^{2, b^{*}}$ \\ ${ }^{1}$ School of Economics \& Management, Beijing University of Aeronautics and Astronautics, Beijing \\ 100191, China \\ ${ }^{2}$ State Grid Tianjin Power Economics \& Technology Research Institute, Tianjin 300171, China \\ aivyin163@163.com, buyujie0802@163.com
}

Keywords: mergers and acquisitions (M\&As); performance; SEM; impact factor

Abstract: In order to improve enterprises' management level, it's necessary to study the impact factors and their weights on M\&As performance of iron and steel enterprises and take the targeted improvement strategies. By using SEM, multiple dependent variables can be calculated simultaneously, independent variables and dependent variable can be allowed to contain measurement error, and the goodness of fit of entire model can be measured. Based on SEM, the correlation degree between different influence factors and the Influence on M\&As performance are analyzed in this paper. The M\&As result of China's iron and steel demonstrates the model effectiveness.

\section{Introduction}

Low market concentration is the main factor to restrict China's iron and steel enterprises to improve competitiveness and reduce overcapacity. It is urgent to evaluate the M\&As performance of iron and steel enterprises scientifically. Since the impact factors of M\&As performance, such as scale economic level, financial health level and M\&As integration ability, have certain subjectivity and fuzziness. Traditional statistical methods have some measurement error, but SEM can solve this problem effectively.

Structural equation modeling (SEM) is a common multivariate statistical method to analyze the relationship between latent variable (LV) and manifest variable (MV) ${ }^{[1]}$, which is widely used in the research of economics, management, psychology, sociology, etc ${ }^{[2]}$. Based on SEM, the result of literature [3] showed that high-quality internal control can improve transnational M\&As performance significantly. However, literature [4] showed that the M\&As performance of most listed companies was not improved. Overall speaking, the literatures about M\&As performance of China's iron and steel enterprises based on SEM are not adequate. More researches are in desperate need.

Based on SEM, the impact factors and their weights on M\&As performance of China's iron and steel enterprises were studied in this paper. This paper provides a reference to improve M\&As performance and strengthen internal controls of iron and steel enterprises.

\section{Principle of SEM}

SEM has two basic models: measured model and structural model. Measured model, made of latent variable and observed variable, is a linear function to observed variable. Structural model is the explanation of causal relationship model of latent variable. Being the reason, latent variable is 
named as exogenous latent variables, using symbols as $\xi$. And being the result, latent variable is named as endogenous latent variables, using symbols as $\eta$.

(1) Measurement model

Measurement equation of the relationship between latent variables and observed variable can be written as follows:

$$
\begin{aligned}
& x=\Lambda_{x} \xi+\delta \\
& y=\Lambda_{y} \eta+\varepsilon
\end{aligned}
$$

Where, $\mathrm{x}$ represents the exogenous observed variable; y represents the endogenous observed variable; $\Lambda_{x}$ represents the factor loading matrix of $\mathrm{x}$ and $\xi ; \Lambda_{y}$ represents the factor loading matrix of $\mathrm{y}$ and $\eta ; \delta$ represents the measurement error of $\mathrm{x} ; \varepsilon$ represents the measurement error of $\mathrm{y}$.

(2) Structure Model

Structural equation of the relationship between latent variables can be written as follows:

$$
\eta=B \eta+\Gamma \xi+\zeta
$$

Where, B represents the relationship between endogenous latent variables; $\Gamma$ represents the impact of exogenous latent variables on endogenous latent variables; $\zeta$ represents the residual error of SEM, as the unexplained part of $\eta$ in SEM.

\section{Variable selection}

M\&As performance of iron and steel enterprises is mainly affected by the scale economic level, financial health and M\&As integration ability. The impact factors can be characterized and described by different observed variable. The symbol, definition and calculation method of variables are shown in Tab.1. 
Tab.1 Symbol, definition and calculation method of variables

\begin{tabular}{|c|c|c|}
\hline Latent variable & Manifest variable & Variable definition and calculation method \\
\hline \multirow{4}{*}{$\begin{array}{l}\text { scale economic } \\
\text { level(SEL) }\end{array}$} & market share $(\mathrm{X} 1)$ & $=$ enterprise's production/industrial total output $* 100 \%$ \\
\hline & bargaining ability (X2) & qualitative index, evaluated by professionals \\
\hline & $\begin{array}{c}\text { comprehensive energy efficiency of } \\
\text { per ton steel (X3) }\end{array}$ & $=$ consumption of standard coal/crude steel production \\
\hline & $\begin{array}{l}\text { enhancing ability of product } \\
\text { add-value (X4) }\end{array}$ & qualitative index, evaluated by professionals \\
\hline \multirow{2}{*}{$\begin{array}{l}\text { financial health } \\
\text { level (FHL) }\end{array}$} & current ratio (X5) & $=$ current assets/current liabilities $* 100 \%$ \\
\hline & asset-liability ratio $(\mathrm{X} 6)$ & $=$ debt $/$ assets $* 100 \%$ \\
\hline \multirow{2}{*}{$\begin{array}{l}\text { M\&As integration } \\
\text { ability (MIA) }\end{array}$} & resource integration efficiency $(\mathrm{X} 7)$ & qualitative index, evaluated by professionals \\
\hline & resource synergy efficiency (X8) & qualitative index, evaluated by professionals \\
\hline \multirow{3}{*}{$\begin{array}{c}\text { M\&As } \\
\text { Performance } \\
\text { (MAP) }\end{array}$} & return on assets (X9) & $=$ net profit/assets $* 100 \%$ \\
\hline & net profit growth rate $(\mathrm{X} 10)$ & $\begin{array}{l}=(\text { current term net profit-beginning term net } \\
\text { profit }) / \text { beginning term net profit } * 100 \%\end{array}$ \\
\hline & profit of per ton steel (X11) & $=$ total profit $/$ crude steel production \\
\hline
\end{tabular}

\section{The SEM of M\&As performance of iron and steel enterprises}

The impact of scale economic level, financial health level and M\&As integration ability on M\&As performance of iron and steel enterprises is studied and the structure equation is established as follows:

$$
M A P=\left[\gamma_{1}, \gamma_{2}, \gamma_{3}\right]\left[\begin{array}{l}
S E L \\
F H L \\
M I A
\end{array}\right]+\zeta
$$

The return on assets(X9), net profit growth rate(X10) and profit of per ton steel (X11) are chosen as indicator variables to measure the M\&As performance of iron and steel enterprises. The structural equation is established as follows:

$$
\left[\begin{array}{l}
X_{9} \\
X_{10} \\
X_{11}
\end{array}\right]=\left[\begin{array}{l}
\alpha_{1} \\
\alpha_{2} \\
\alpha_{3}
\end{array}\right] \times M A P+\left[\begin{array}{l}
e_{9} \\
e_{10} \\
e_{11}
\end{array}\right]
$$

The structural equation of SEL, FHL, MIA are established as follows:

$$
\left[\begin{array}{l}
X_{1} \\
X_{2} \\
X_{3} \\
X_{4} \\
X_{5} \\
X_{6} \\
X_{7} \\
X_{8}
\end{array}\right]=\left[\begin{array}{lll}
\beta_{1} & 0 & 0 \\
\beta_{2} & 0 & 0 \\
\beta_{3} & 0 & 0 \\
\beta_{4} & 0 & 0 \\
0 & \beta_{5} & 0 \\
0 & \beta_{6} & 0 \\
0 & 0 & \beta_{7} \\
0 & 0 & \beta_{8}
\end{array}\right]\left[\begin{array}{l}
S E L \\
F H L \\
M I A
\end{array}\right]+\left[\begin{array}{l}
e_{1} \\
e_{2} \\
e_{3} \\
e_{4} \\
e_{5} \\
e_{6} \\
e_{7} \\
e_{8}
\end{array}\right]
$$




\section{Case analysis}

Mergers and acquisitions cases of iron and steel enterprises in recent years are taken as an example in this paper. Based on the operating data in 2005-2014, factors affecting M\&As performance of iron and steel enterprises are analyzed. After standardized processing, the raw data is put into the theoretical model described by Amos Graphics.

Non-standardized regression coefficient and significance test are shown in Tab.2.

Tab.2 Non-standardized regression coefficient table

\begin{tabular}{|lrl|rrrc|}
\hline & & & Estimate & \multicolumn{1}{c}{ S.E. } & C.R. & P \\
\hline M\&As Performance & $<---$ & Scale Economic Level & 0.605 & 0.301 & 2.010 & $* * *$ \\
M\&As Performance & $<---$ & M\&As Integration ability & 0.886 & 0.327 & 2.709 & $* * *$ \\
M\&As Performance & $<---$ & Financial Health Level & 0.503 & & & \\
X6 & $<---$ & Financial Health Level & 1.172 & 0.551 & 2.127 & $* * *$ \\
X5 & $<---$ & Financial Health Level & 1.000 & & & \\
X2 & $<---$ & Scale Economic Level & 1.000 & & & \\
X1 & $<---$ & Scale Economic Level & 0.277 & 0.061 & 4.541 & $* * *$ \\
X9 & $<---$ & M\&As Performance & 1.000 & & & \\
X10 & $<---$ & M\&As Performance & 12.387 & 5.467 & 2.266 & $* * *$ \\
X3 & $<---$ & Scale Economic Level & 0.056 & 0.019 & 2.947 & $* * *$ \\
X4 & $<---$ & Scale Economic Level & 0.651 & 0.118 & 5.517 & $* * *$ \\
X11 & $<---$ & M\&As Performance & 0.555 & 0.146 & 3.801 & $* * *$ \\
X8 & $<---$ & M\&As Integration ability & 0.979 & 0.057 & 17.175 & $* * *$ \\
X7 & $<---$ & M\&As Integration ability & 1.000 & & & \\
\hline
\end{tabular}

All the C.R values are over 1.96, indicating that the regression coefficients have reached the significant level. The standardized estimated values of the corresponding latent variable and observed variables are shown in Fig.1.

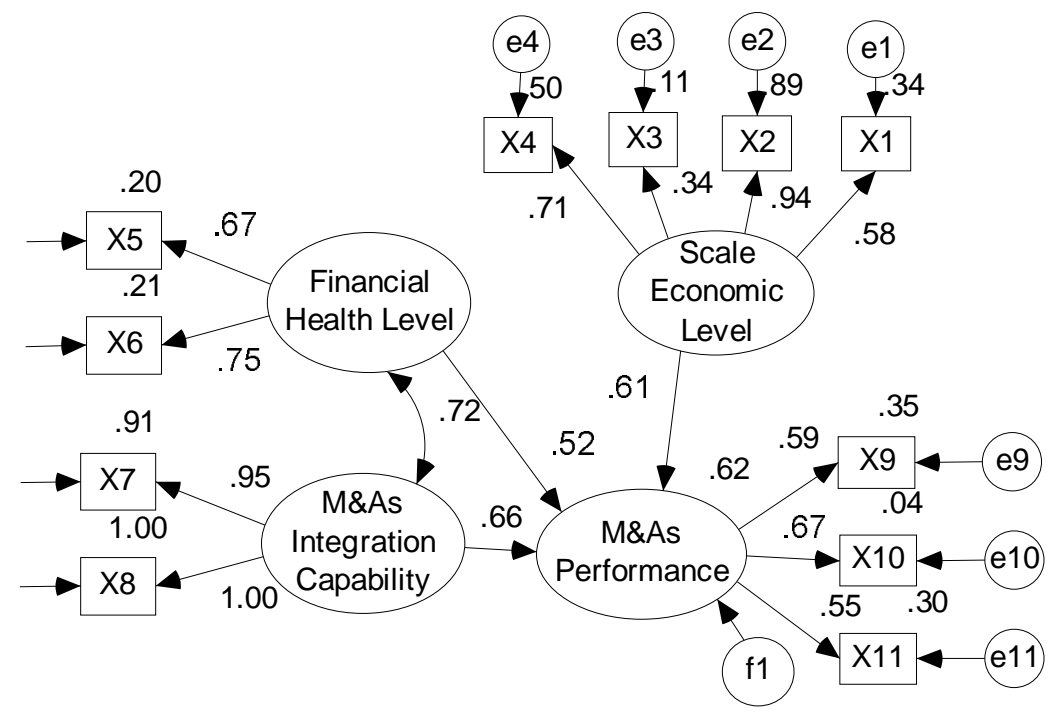

Fig.1 SEM of M\&As Performance

Most estimated values of latent variable and its observed variables are between 0.5 and 1 , indicating that the latent variable can be effectively reflected by observed variables. 


\section{Conclusions}

Based on SEM, the impact of scale economic level, financial health and M\&As integration ability on M\&As performance in the process of iron and steel enterprises' mergers and acquisitions is analyzed in this paper. Research shows that the iron and steel enterprise can effectively achieve higher M\&As performance if it has a high internal resource integration, interoperability and high market power. Therefore, the government should encourage such enterprises with higher market power and resource allocation ability to participate in M\&As and improve M\&As performance in the future.

\section{Reference}

[1]Anderson J C, Gerbing D W. Structural Equation Modeling in Practice: A Review and Recommended Two-Step Approach [J]. Psychological Bulletin,1988,103(3): 411-423.

[2]Rebecca Weston. A Brief Guide to Structural Equation Modeling[J]. The Counseling Psychologist, 2006(34):719-751

[3]Yang Mian-zhi, Sun Chao. Internal Controls, Political Risk and Transnational M\&A Performance: an Empirical Analysis Based on SEM[J]. Scientific decision-making, 2014(4):1-15

[4]Lin De-qin. An Empirical Study on Performance of Listed Companies' Merger based on SEM [J]. Productivity Research, 2011(7): 170-172 